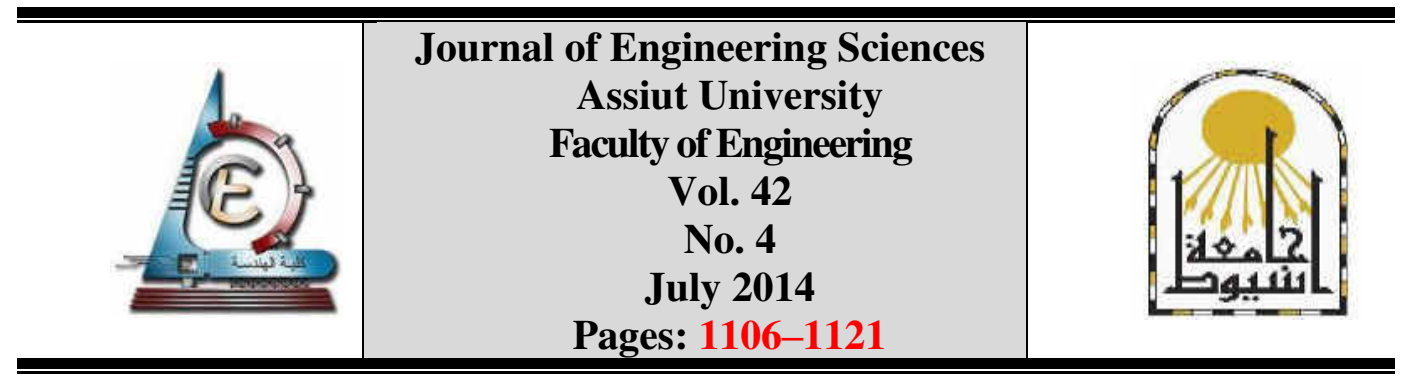

\title{
THE OPTIMAL METHOD FOR CLASSIFYING HIGH RESOLUTION SATELLITE IMAGES IN EGYPT ENVIRONMENT
}

\author{
Faten A. Mostafa $^{1, *}$, Yasser G. Mostafa ${ }^{2}$, Mohamed A. Yousef ${ }^{3}$ \\ ${ }^{1,3}$ Mining and Metallurgy Eng. Dpt. Faculty of Engineering, Assiut University \\ ${ }^{2}$ Civil Eng. Dpt. Faculty of Engineering, Sohag University \\ Received 17 April 2014, Accepted 14 June 2014
}

\begin{abstract}
The remote sensing society is currently offering a wide variety of digital images that cover most of the Earth's surface. The up-to-date image data is a promising tool for producing accurate maps. To maximize the benefit of such data, automatic and efficient classification methods are investigated. For the past years, traditional pixel-based classification has been used. Currently, a recent classification concept, object-based classification, has been prospected. The recent concept's basic principle is to make use of important information (shape, texture and contextual information) which is only in meaningful image objects and their mutual relationships. The main aim of the present work is to find the most suitable technique from the available ones for feature extraction which can be applied for Egyptian environment.

For this study, high resolution satellite image from IKONOS satellite was used to carry out the image classifications. The ground reference data were collected from field observations and personal knowledge. At the present work, the methodology focuses on comparing between two classifications techniques through application on four test areas with different specifications with respect to its planning. The first technique is the traditional pixel-based image analysis and the second one is the object-oriented image analysis. Software ERDAS V.9.2 was used for pixelbased image analysis and classification. The object-oriented image classification was performed through eCognition Developer software V.8.0. Accuracy of each one of both techniques was evaluated through overall accuracy and kappa coefficient from the error matrix and then compared to each other. Results of this work showed that object-based image analysis has more advantages than the Pixel-based one. Also, it is found that as the more planned area as the higher results accuracy.
\end{abstract}

Keywords: Pixel-based analysis, Object-based analysis, Classification, Segmentation.

\footnotetext{
* Corresponding author.

Email address: faten433@yahoo.com
} 


\section{Introduction}

Remotely sensed image analysis is a challenging task. One of popular and commonly used technique to image analysis is image classification. The purpose of image classification is to label the pixels in the image with meaningful information of the real world [1]. Through classification of digital remote sensing image, the thematic maps bear the information which can be obtained such as land cover type; vegetation type etc [2].

In the traditional pixel-based classification methods only the pixels spectral information is used to extract surface features. This approach can not satisfy highresolution satellite image classification precision and produce great data redundancy [3]. Recently, Object-oriented information extraction depends on spectrum character, geometry and structure information. This approach interprets an image that is represented not only by single pixels, but also in meaningful image objects and their mutual relationships. It provides an inclusive bundle of creative features and techniques for automated image analysis [4]. It must be referred that, several works are accomplished by other persons for comparison between both above mentioned techniques in their study areas. However, previous studies show some inconsistent results. Some studies have found a significantly higher accuracy for the object-oriented approach [5, $6 \& 7]$, while other investigations reported the two approaches produced similar results with comparable accuracy $[8,9]$. Areas planning are not treated through these preceding workings. The present work aims mainly to compare between pixel/and object-based techniques with respect to the degree of areas planning at Egypt to find out its influence on the performance of classification methods.

The specifications of study areas are described in Section (2). Section (3) illustrates the data and methodology which are handled here. Both classification techniques (Pixel-based and Object-based ones), which are applied at the present study, are detailed in sections (4 $\& 5)$ respectively. Results and discussion are demonstrated through section (6). Section (7) contains the conclusion.

\section{Study area}

The study area is located at Assiut governorate, Egypt. Its location is directly near the Nile River. It lies between $26^{\circ} 40^{\prime} \mathrm{N} \& 27^{\circ} 30^{\prime} \mathrm{N}$ and $30^{\circ} 41^{`} \mathrm{E} \& 31^{\circ} 31^{\prime} \mathrm{E}$. The study area is composed of various features such as road networks, residential area, vegetation, bare soil and water bodies (Figure1).

Four different test areas were selected to discuss the possibility of extracting the features from the image. These test areas as shown in (Figure -1.a, b, c \& d, respectively) are:

1) Assiut University Campus.

This area is characterized as a good planned area including large building with regular shapes. Its area is $2.1 \mathrm{~km}^{2}$.

2) El-Zahraa area.

It is characterized as semi-planned area with high-density. It contains small streets and its buildings are residential buildings of up to 6 floors. Its area is $1.4 \mathrm{~km}^{2}$. 
Faten A. Mostafa et al., The optimal method for classifying high resolution satellite images .....

3) El-Walidia area.

This area is described as unplanned and high-density area containing small and randomly shaped buildings and narrow streets. Its area is $1.7 \mathrm{~km}^{2}$.

4) Bani-mor area.

It is a village which represents a sample for the Egyptian rural village. It is specified by small buildings with irregular shapes and distribution. Its area is $0.8 \mathrm{~km}^{2}$.

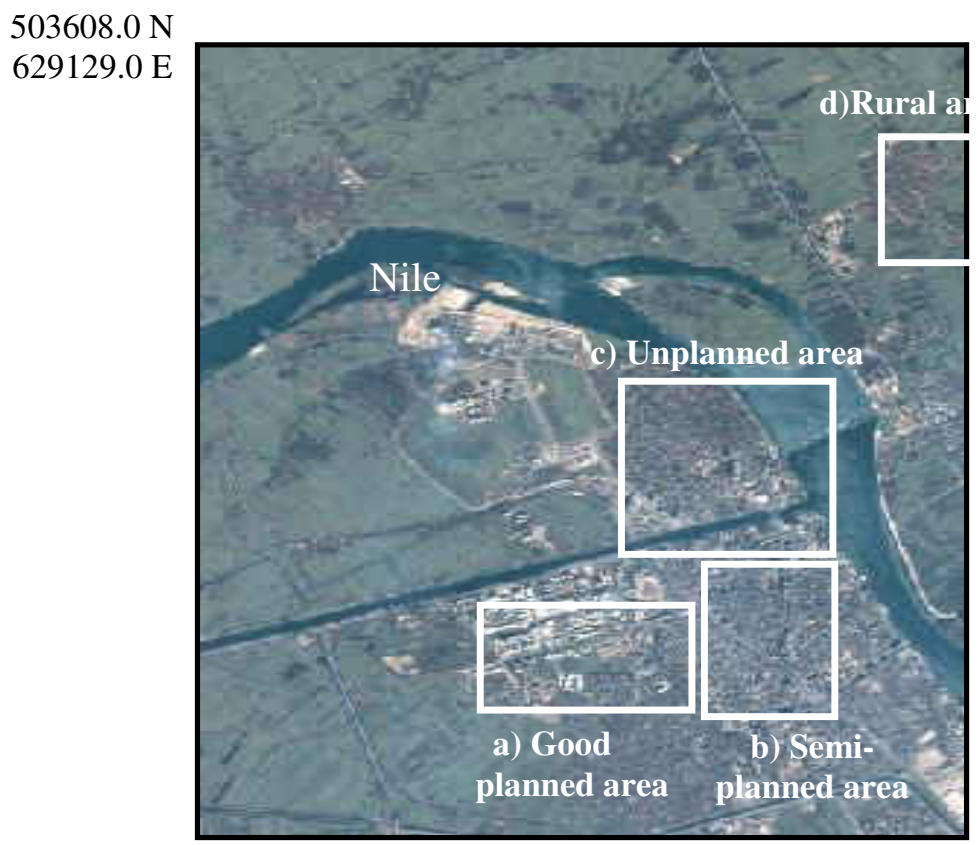

$496168.0 \mathrm{~N}$

$634679.0 \mathrm{E}$

Fig. 1. The IKONOS image of the study area-Assiut, Egypt

\section{Data and methodology}

IKONOS Panchromatic (1m) and Multispectral (4m) images are used for this research. These images are acquired on 17th February 2006 at 08:59 GMT with a Nominal Collection Azimuth of 315.7160 degrees, Nominal Collection Elevation of 61.15005 degrees, Sun Angle Azimuth of 154.1060 degrees, and Sun Angle Elevation of 47.13676 degrees.

In order to realize the aim of this research, geometric correction is necessary. The images were corrected geometrically and fitted to a known coordinate system. The produced corrected images were integrated together to obtain a high spatial and spectral quality satellite image which is known as Pan-Sharpened image. After that, pixel-based image classification was performed on the study area using the Minimum distance, Maximum Likelihood and Mahalanobis Distance methods. Through comparing the results of the three methods, the most accurate one be selected for this research.

Object-based classification starts by segmenting the entire image into objects, then classification process of these objects is carried out. In this research object-based classification process is controlled by a knowledge base that describes the characteristics 
of output object classes (in the form of fuzzy membership functions). In order to compare the accuracy of the classification results created by the two methods, pixel-based and object-based, error matrix which based on test areas is used. Both pixel-based and objectbased image analysis results are evaluated with a set of the same random sampled reference data.

\subsection{Image geo-referencing}

In order to prepare the images for an accurate classification comparison, image georeferencing is required. Image geo-referencing is the process of fitting remotely sensed data to a known, or common, coordinate system and transforming the data to this new system. These two steps are known as rectification and resampling [10]. For this purpose, the images were rectified to Transverse Mercator, Helmert, and Old Egypt 1907 coordinate system. A number of 13 control points as well as 12 check points of one tenth meter accuracy were used. These points were collected by using the PROMARK3 Differential Global Positioning System (DGPS) using the features that could be identified accurately, such as road intersections, bridges, and canal's intakes. These points have been taken to be in a nearly uniform distribution. Third order polynomial transformation method was used to provide accuracy through Root Mean Square Errors (RMSE) in the check point of 1.1 pixel. The resampling process was carried out by using the nearest neighbor method.

\subsection{Data fusion}

To take advantage of complementary spatial/spectral resolution characteristics, data fusion techniques are needed. Data fusion techniques allow the integration of different information sources [11], [12]. In many remote sensing and mapping applications, data fusion technique is an important issue for the purpose of feature extraction. It is a suitable technique in this respect.

Image merging essentially occurs when the involved images have the same spatial resolution. Thus, multispectral images need to be resampled such that they have the same spatial resolution with the panchromatic image. In the present study the nearest neighbor method is selected for resampling to keep the color content of the original multispectral image unchanged. That method is the simplest one among other resampling methods such as bilinear interpolation, cubic convolution methods [13]. There are several algorithms for image fusion like Principal Component Analysis (PCA), Intensity-Hue-Saturation (IHS) and Brovey Transform. Those three different techniques would be used at this study. The best one that can effectively combine the two images is to be selected in this research. Occasionally, there is no effective way to evaluate the merging result either qualitatively or quantitatively. Visual inspection is still the most common method to evaluate the merging result qualitatively. Additionally, several quantitative indexes such as mean, median, standard deviation, correlation coefficient, etc., can be also used to assess the merging result quantitatively [14].

\section{Pixel-based classification}

\subsection{Unsupervised classification}

Unsupervised classification is fast and it has the ability to analyze the image spectral 
statistics completely and systematically. Thus, unsupervised classification creates a useful indication of detectable classes for supervised classification.

\subsection{Supervised classification}

In supervised classification, there are some basic steps that are to be followed. Firstly is selecting the training samples which are representative for these information classes. Secondly, is to perform classification after specifying the training samples set and specifying classification algorithms. Thirdly, is assessing the accuracy of the classified image through analyzing the confusion matrix which is generated through random sampling.

The classical pixel-based methods which has been used are minimum-distance, maximum likelihood and Mahalanobis algorithms. For the purpose of accuracy assessment, choosing the number of samples of the reference data based on a rule of thumb which recommends that at least 50 samples per class included in error matrix [15],[16], is taken into consideration. Furthermore, the number of samples is based on the relative importance of that category for a particular application and the variability within each category. At this research, the test areas ranging from 0.8 to $2.1 \mathrm{~km}^{2}$ and the number of classes are 6 classes. So, nearly 300 samples are taken according to the considered area as well as according to satisfy the importance and variability of each class. Then the results will be compared between them in order to select the most accurate one. That method is selected for this research to be applied about the four test areas. The classes at this respect are road, building, vegetation, water, bare soil and shadow. The shadow class can be reclassified to roads and other man-made classes according to the shape [17].

\section{Object-based classification}

Object-based image analysis comprises two parts: 1) image segmentation and 2) object classification based on objects features in spectral and spatial domains. By segmentation, the image is divided into homogeneous, continuous and contiguous objects. Several parameters are used to affect the segmentation result. These parameters are scale, colour criterion, shape criterion, compactness and smoothness [18]. At the present work, the segmentation criterion combinations uses are: scale factor 25, colour 0.9, shape 0.1 , compactness 0.5 and smoothness 0.5 . The resulting objects also depend on the image data. These values are taken as the best ones resulting from trial and error method which is performed by the author of the present work.

The image objects can then be described and classified by an extensive variety of attributes that include colour, texture, form and context properties in several forms. The rule set (algorithm) in a decision tree was developed to identify land cover area. All these attributes can be applied and combined in a membership function for each class to refine the classification until getting optimal results. The usage of membership values to separate the classes is the solution for the conflict problem between them. In some cases, no rule can be generated to discriminate between classes and the misclassifications cannot be avoided. The near infrared band is important in distinguishing most of the land cover types such as agriculture class. Usually, the attributes range is defined with the upper and lower limits.

Image objects within the defined limit are assigned to a specific class, while those outside of the feature range are assigned to a different class (or left unclassified). The following table (Table 1) shows the considered features used in the classification process for the planned area. The other areas follow the same style. 
Table 1.

The attributes used to aid the classification process.

\begin{tabular}{|c|c|c|}
\hline Class & $\begin{array}{l}\text { The considered main limits to } \\
\text { separate between classes }\end{array}$ & $\begin{array}{l}\text { The considered limits for cleaning the } \\
\text { classification }\end{array}$ \\
\hline Water & $\begin{array}{l}\text { Spectral information: Mean } \\
\text { NIR } \\
\text { ( water }<170 \text { ) }\end{array}$ & Shape index; size: area (water>7820pixel) \\
\hline Building & $\begin{array}{l}\text { Spectral information: Mean } \\
\text { brightness all layer. } \\
\text { (built }>=480 \text { ) }\end{array}$ & $\begin{array}{l}\text { Customized feature: green ratio to refine } \\
\text { building from vegetation } \\
\text { GR= (mean green }) /(\text { mean blue }+ \text { mean red }) \\
(\mathrm{GR}<930 \text { unclassified) } \\
\text { Context: rel. Border to unclassified } \\
\text { (built }>=50 \%) \\
\text { Shape index; size: area(built }>860 \text { pixel) }\end{array}$ \\
\hline Vegetation & $\begin{array}{l}\text { NDVI }=(\text { mean nir-mean red }) / \\
\text { (mean nir }+ \text { mean red) } \\
\text { (vegetation }>=750)\end{array}$ & \\
\hline $\begin{array}{l}\text { Other man- } \\
\text { made (road, } \\
\text { and bare soil) }\end{array}$ & $\begin{array}{l}\text { Spectral information: Mean } \\
\text { brightness all layer. } \\
\text { (shadow<=250)(road<=234) } \\
\text { (bare soil<=330) }\end{array}$ & $\begin{array}{l}\text { Shape index; size: area, length/width ratio ( }>= \\
2.8 \text { roads), Context: rel. border to unclassified }\end{array}$ \\
\hline
\end{tabular}

At the end of classification the objects of shadow are reclassified to roads in object oriented.

\section{Results and discussion}

\subsection{Data fusion}

Depending on the visual inspection only, there are no clear differences between the three merged images and each leads to good visual results. The assessment of spectral quality checked by comparing the merged image with the original multi-spectral image to see any image radiometry of the three merged images is as identical as possible to the radiometry of the original multi-spectral image.

Table (2) includes the resulting statistical parameters of the histogram for the RGB channels of the original image and the three merged images. From the shown results, it is found that the best results were obtained from the IHS transformation fusion method which mostly is identical as in the original multi-spectral image. The accuracy assessment shows that it gives the highest standard deviation (107.730, 143.054 and 161.316) and highest correlation coefficient $(0.996$, 0.989 and 0.908 ). Accordingly IHS method selected for this research.

\subsection{Unsupervised classification}

The result of unsupervised classification for the study area, combining the spectral clusters, is that 6 classes were identified. They are building, roads, bare soil, vegetation, water and high residential area.

\subsection{Supervised classification}

Pixel-based image classification result for the study area through visual inspection showed better results for the Maximum Likelihood and Mahalanobis Distance classifiers than the Minimum Distance classifier. Statistically, Maximum Likelihood obtains $84.80 \%$ 
Faten A. Mostafa et al., The optimal method for classifying high resolution satellite images .....

overall accuracy and 0.8122 kappa coefficients. Mahalanobis Distance obtains 82.40\% overall accuracy and 0.7759 kappa coefficients. Minimum Distance classifier obtains overall Accuracy $73.60 \%$ and the Kappa Coefficient was 0.6656. Also, the producer's accuracy for almost classes in the Maximum Likelihood classifier was greater than $82 \%$. Accordingly, Maximum Likelihood classifier was selected at this research for the four test areas.

\subsection{The comparison of pixel-based and object-based analysis results}

Pixel-based and object-based image analysis approaches have been performed by classifying the pan-sharpened IKONOS image. The accuracy of the classification results have been assessed by the error matrix. Both pixel-based and object-based image analysis results were evaluated with a set of the same random sampled reference data.

Results and comparison of both techniques for each one of the test areas are illustrated as follows:

\subsubsection{Good planned area}

For pixel-based classification table (3) shows the error matrix of the Maximum Likelihood supervised classification. It can be seen that the overall accuracy is $86.42 \%$ and overall kappa statistics is 0.8369 . Information class of water has both higher producer's accuracy (96.08\%) and user's accuracy (94.23\%). Some water pixels class was classified to shadow class. The reason of this confusion due to the similarity in spectral reflectance between shadow (dark area) and water (Figure 2.a, b).

The information classes of the building, road, bare soil, shadow and vegetation have a producer's accuracy $(89.29 \%, 77.59 \%, 91.07, \%, 84.00 \%$ and $81.13 \%$ respectively) and user's accuracy $(81.97 \%, 84.91 \%, 82.26 \%, 87.50 \%$ and $89,58 \%$ respectively). There is some confusion among these classes. The reason of this confusion is that there is similarity in spectral reflectance among the building (some materials in the roof), road (coating the edges of sidewalk), vegetation (particularly dark trees), bare soil (dry or moisture), and shadow.

\section{Table 2.}

The resulting statistical parameters of histogram of RGB channels in original multispectral image and in merged images

\begin{tabular}{|c|c|c|c|c|c|c|c|c|c|c|c|c|c|c|}
\hline \multirow{2}{*}{$\begin{array}{l}\text { Statistical } \\
\text { parameter }\end{array}$} & \multicolumn{4}{|c|}{ Multi-spectral Image } & \multicolumn{4}{|c|}{ PCA Fused Image } & \multicolumn{3}{|c|}{ HIS } & \multicolumn{3}{|c|}{ Brovey Fused Image } \\
\hline & Red & Green & Blue & NIR & Red & Green & Blue & NIR & Red & Green & Blue & Red & Green & Blue \\
\hline Mean & 291.173 & 329.968 & 252.773 & 534.796 & 289.045 & 348.879 & 230.235 & 1666.588 & 332.74 & 393.566 & 327.076 & 257.473 & 134.429 & 119.171 \\
\hline Median & 282.37 & 306.74 & 209.96 & 501.81 & 276.56 & 317.9 & 184.97 & 1645.2 & 301.73 & 409.22 & 346.31 & 176.11 & 140.3 & 122.57 \\
\hline $\begin{array}{l}\text { Standard } \\
\text { Deviation }\end{array}$ & 79.641 & 111.424 & 126.017 & 281.675 & 72.554 & 104.323 & 124.693 & 136.299 & 107.73 & 143.054 & 161.316 & 105.159 & 53.570 & 45.129 \\
\hline $\begin{array}{l}\text { Correlation } \\
\text { Coefficient }\end{array}$ & 1.000 & 1.000 & 1.000 & 1.000 & 0.995 & 0.892 & 0.894 & 0.891 & 0.996 & 0.989 & 0.908 & 0.861 & 0.902 & 0.638 \\
\hline
\end{tabular}

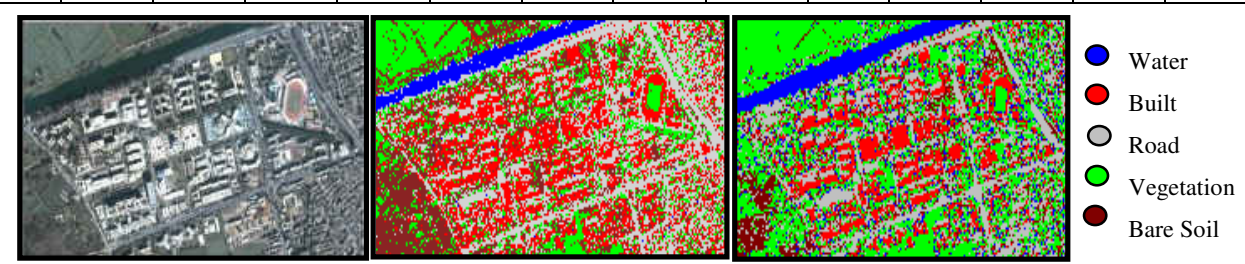
a) Original image
b) Pixel classification
c) Object

Fig. 2. Pixel-based and obiect-based classification results of the 
Table 3.

The confusion matrix for pixel-based classification of the good planned area.

\begin{tabular}{|c|c|c|c|c|c|c|c|c|c|}
\hline $\begin{array}{l}\text { Classified } \\
\text { Data }\end{array}$ & 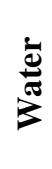 & مُ & 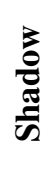 & 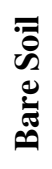 & 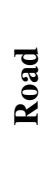 & 象 & $\begin{array}{l}\text { Total } \\
\text { Row }\end{array}$ & $\begin{array}{l}\text { Producers } \\
\text { Accuracy }\end{array}$ & $\begin{array}{c}\text { Users } \\
\text { Accuracy }\end{array}$ \\
\hline Water & 49 & 0 & 3 & 0 & 0 & 0 & 52 & $96.08 \%$ & $94.23 \%$ \\
\hline Vegetation & 0 & 43 & 1 & 2 & 2 & 0 & 48 & $81.13 \%$ & $89.58 \%$ \\
\hline Shadow & 2 & 0 & 42 & 0 & 3 & 1 & 48 & $84.00 \%$ & $87.50 \%$ \\
\hline Bare Soil & 0 & 6 & 0 & 51 & 3 & 2 & 62 & $91.07 \%$ & $82.26 \%$ \\
\hline Road & 0 & 2 & 1 & 2 & 45 & 3 & 53 & $77.59 \%$ & $84.91 \%$ \\
\hline Building & 0 & 2 & 3 & 1 & 5 & 50 & 61 & $89.29 \%$ & $81.97 \%$ \\
\hline $\begin{array}{l}\text { Total } \\
\text { Column }\end{array}$ & 51 & 53 & 50 & 56 & 58 & 56 & 324 & & \\
\hline
\end{tabular}

Overall accuracy $86.42 \%$ overall kappa statistics 0.8369

In object-based method, the classified objects (Figure- 2.c) are not only assigned to one class, but also get a detailed list with the membership values of each class in the class hierarchy. An image object is assigned to the class with highest membership value. It is significant for the quality of a classification result. The highest membership value of an image object is absolutely high, indicating that the image object attributes are well suited to at least one of the class description. If an image object has memberships in more than one class, the classification with the highest assignment values is taken as the best classification result. Table (4) shows the result of the accuracy assessment for object-based classification.

Table 4.

The confusion matrix for object-based classification of the good planned area.

\begin{tabular}{|c|c|c|c|c|c|c|c|c|c|}
\hline Classified Data & $\sum^{\frac{\pi}{\pi}}$ & 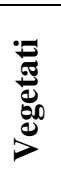 & $\frac{8}{\tilde{\sigma}}$ & : & 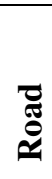 & 象 & Total Row & $\begin{array}{l}\text { Producers } \\
\text { Accuracy }\end{array}$ & $\begin{array}{l}\text { Users } \\
\text { Accuracy }\end{array}$ \\
\hline Water & 51 & 0 & 0 & 0 & 0 & 0 & 51 & 100 & $100.00 \%$ \\
\hline Vegetation & 0 & 52 & 1 & 0 & 1 & 0 & 54 & $98.11 \%$ & $96.30 \%$ \\
\hline Shadow & 0 & 0 & 47 & 0 & 2 & 0 & 49 & $94.00 \%$ & $95.92 \%$ \\
\hline Bare Soil & 0 & 1 & 0 & 51 & 1 & 0 & 53 & $91.07 \%$ & $96.23 \%$ \\
\hline Road & 0 & 0 & 2 & 4 & 54 & 0 & 60 & $93.10 \%$ & $90.00 \%$ \\
\hline Building & 0 & 0 & 0 & 1 & 0 & 56 & 57 & $100.00 \%$ & $98.25 \%$ \\
\hline Total Column & 51 & 53 & 50 & 56 & 58 & 56 & 324 & & \\
\hline
\end{tabular}

Overall accuracy $95.99 \%$

overall kappa statistics 0.9518

From Table (4) it can be seen that the overall accuracy is $95.99 \%$ and overall kappa statistics is 0.9518. Taking into consideration the producer's and user's accuracy of individual class, all the information classes have high or relatively high producer's and user's accuracy. For the water class each of both the producer's and user's accuracy is $100 \%$. Water bodies did not have conflicts with the other classes. The reason for there is that the pixels of 
the turbulent water is embedded in quiet water objects and then classified to water class, thus the object-based analysis overcome the turbulent water problem. There is some confusion between bare soil, road and vegetation (particularly dark green trees) due to similarity in brightness between them. It was found that trees are always along the roads. By image segmentation, trees pixels which are located along the boundary of the road could be grouped into the same objects with pixels of road. By object-based classification the tree's pixels could be classified as roads being in the same object, and vice versa.

\subsubsection{Semi-planned and high residential area}

Pixel-based image classification method (Figure- 3.b) shows misclassification in all classes, particularly in road and building classes. The error matrix of this method was given in table (5). From Table (5) it can be seen that the overall accuracy is $73.60 \%$ and overall kappa statistics is 0.6829 . Building and road Classes have the lowest producer's accuracy (51.35\% and 68.57\% respectively) and user's accuracy (59.38\% and $68.57 \%$ respectively). The reason for this low accuracy in general be the same as it was mentioned in subsection (6.4.1). In addition to that, the existence of well planned building and roads enhances the ability to extract this features from the image as in the previous planned area, not only because of the size and shape of the features but also because the density of it.

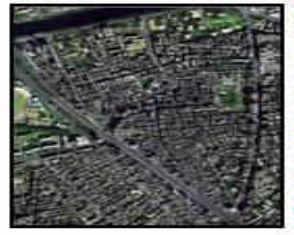

a) Original image

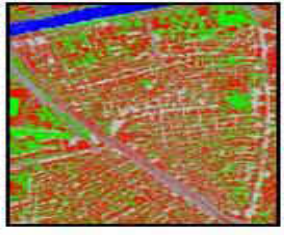

b) Pixel classification

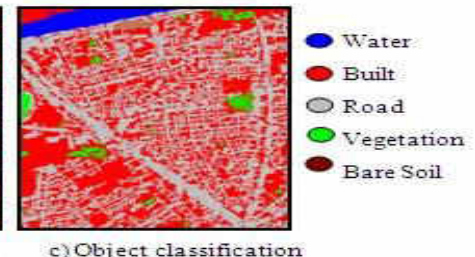

c) Object classification

Fig. 3. Pixel-based and object-based classification results of semi-planned area.

\section{Table 5.}

The confusion matrix for pixel-based classification of the semi-planned area

\begin{tabular}{|c|c|c|c|c|c|c|c|c|c|}
\hline $\begin{array}{l}\text { Classified } \\
\text { Data }\end{array}$ & $\frac{\bar{d}}{\underbrace{\pi}}$ & 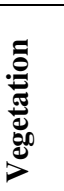 & ) & 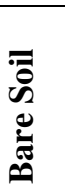 & 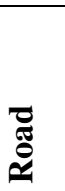 & $\stackrel{000}{\Xi}$ & $\begin{array}{l}\text { Total } \\
\text { Row }\end{array}$ & $\begin{array}{l}\text { Producers } \\
\text { Accuracy }\end{array}$ & $\begin{array}{l}\text { Users } \\
\text { Accuracy }\end{array}$ \\
\hline Water & 48 & 0 & 1 & 0 & 1 & 0 & 50 & $96.00 \%$ & $96.00 \%$ \\
\hline Vegetation & 0 & 42 & 9 & 3 & 1 & 5 & 60 & $79.25 \%$ & $70.00 \%$ \\
\hline Shadow & 2 & 1 & 51 & 0 & 0 & 0 & 54 & $72.86 \%$ & $94.44 \%$ \\
\hline Bare Soil & 0 & 3 & 1 & 49 & 8 & 16 & 77 & $84.48 \%$ & $63.64 \%$ \\
\hline Road & 0 & 0 & 3 & 4 & 48 & 15 & 70 & $68.57 \%$ & $68.57 \%$ \\
\hline Building & 0 & 7 & 5 & 2 & 12 & 38 & 64 & $51.35 \%$ & $59.38 \%$ \\
\hline $\begin{array}{l}\text { Total } \\
\text { Column }\end{array}$ & 50 & 53 & 70 & 58 & 70 & 74 & 375 & & \\
\hline
\end{tabular}

Overall accuracy $73.60 \%$

overall kappa statistics 0.6829

Object-based image classification method (Figure- 3.c) shows significant misclassification in the area of the roof building. The error matrix of this method is given in table (6). It can be seen that the overall accuracy is $85.60 \%$ and overall kappa statistics is 0.8269 . Building class has the lowest producer's accuracy $(72.97 \%)$. The reason for this 
low accuracy is that there is a similarity in spectral reflectance between the roof of settlement building materials and other classes such as road and shadow. By image segmentation pixels of roof building grouped into road or shadow objects; this could be lead to the miss-classification between these three classes.

Table 6.

The confusion matrix for object-based classification of the semi-planned

\begin{tabular}{|c|c|c|c|c|c|c|c|c|c|}
\hline $\begin{array}{l}\text { Classified } \\
\text { Data }\end{array}$ & $\frac{\dot{ \pm}}{\pi}$ & & 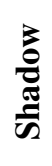 & 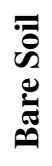 & 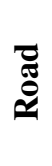 & 象 & $\begin{array}{l}\text { Total } \\
\text { Row }\end{array}$ & $\begin{array}{l}\text { Producers } \\
\text { Accuracy }\end{array}$ & $\begin{array}{l}\text { Users } \\
\text { Accuracy }\end{array}$ \\
\hline Water & 50 & 0 & 5 & 0 & 0 & 0 & 55 & $100.00 \%$ & $90.91 \%$ \\
\hline Vegetation & 0 & 47 & 0 & 0 & 0 & 14 & 61 & $88.68 \%$ & $77.05 \%$ \\
\hline Shadow & 0 & 1 & 58 & 7 & 0 & 2 & 68 & $82.86 \%$ & $85.29 \%$ \\
\hline Bare Soil & 0 & 0 & 1 & 49 & 7 & 0 & 57 & $84.48 \%$ & $85.96 \%$ \\
\hline Road & 0 & 2 & 5 & 0 & 63 & 4 & 74 & $90.00 \%$ & $85.14 \%$ \\
\hline Building & 0 & 3 & 1 & 2 & 0 & 54 & 60 & $72.97 \%$ & $90.00 \%$ \\
\hline $\begin{array}{l}\text { Total } \\
\text { Column }\end{array}$ & 50 & 53 & 70 & 58 & 70 & 74 & 375 & & \\
\hline
\end{tabular}

Overall accuracy $85.60 \%$

overall kappa statistics 0.8269

\subsubsection{Unplanned and high residential area}

Pixel-based image classification method shows misclassification in all classes as shown in (Figure- 4.b). The error matrix of this method is included in table (7). It can be seen that the overall accuracy is $69.21 \%$ and overall kappa statistics is 0.6294 . Building and road classes have the lowest producer's accuracy (61.43\% and $43.64 \%$ respectively) and user's accuracy (60.56\% and 58.54\% respectively). The reason for this low accuracy in buildings and roads is that the buildings have small areas with unclear roofs and the roads are narrow. Also, it should be noticed that the major roads have a large confusion with buildings.

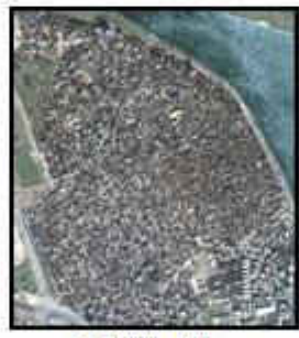

a) Original image

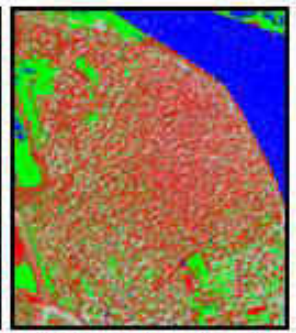

b) Pixel classification

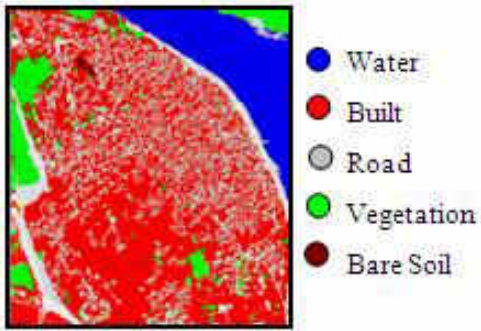

c) Object classification

Fig. 4. Pixel-based and object-based classification results of the unplanned area 
Faten A. Mostafa et al., The optimal method for classifying high resolution satellite images .....

Table 7.

The confusion matrix for pixel-based classification of the un-planned area

\begin{tabular}{|c|c|c|c|c|c|c|c|c|c|}
\hline $\begin{array}{l}\text { Classified } \\
\text { Data }\end{array}$ & ${ }_{\bar{\nu}}^{\bar{d}}$ & & 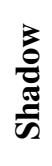 & 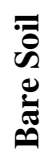 & 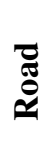 & 胞 & $\begin{array}{l}\text { Total } \\
\text { Row }\end{array}$ & $\begin{array}{l}\text { Producers } \\
\text { Accuracy }\end{array}$ & $\begin{array}{c}\text { Users } \\
\text { Accuracy }\end{array}$ \\
\hline Water & 55 & 0 & 0 & 0 & 5 & 3 & 63 & $90.16 \%$ & $87.30 \%$ \\
\hline Vegetation & 0 & 40 & 3 & 4 & 2 & 5 & 54 & $78.43 \%$ & $74.07 \%$ \\
\hline Shadow & 0 & 5 & 41 & 4 & 6 & 7 & 63 & $75.93 \%$ & $65.08 \%$ \\
\hline Bare Soil & 0 & 1 & 2 & 33 & 9 & 4 & 49 & $66.00 \%$ & $67.35 \%$ \\
\hline Road & 6 & 0 & 0 & 3 & 24 & 8 & 41 & $43.64 \%$ & $58.54 \%$ \\
\hline Building & 0 & 5 & 8 & 6 & 9 & 43 & 71 & $61.43 \%$ & $60.56 \%$ \\
\hline $\begin{array}{l}\text { Total } \\
\text { Column }\end{array}$ & 61 & 51 & 54 & 50 & 55 & 70 & 341 & & \\
\hline
\end{tabular}

Overall accuracy $69.21 \%$

overall kappa statistics 0.6294

Object-based image classification method (Figure -4.c) showed that the major roads are classified as better than of which resulted from the pixel-based one. Also, there are misclassification in lower part of the study area which consists of the secondary roads and building because of the confusion between them. The error matrix of this method is contained in table (8). It can be seen that the overall accuracy is $82.70 \%$ and overall kappa statistics is 0.7913 .

Table 8.

The confusion matrix for object-based classification of the un-planned area

\begin{tabular}{|c|c|c|c|c|c|c|c|c|c|}
\hline $\begin{array}{l}\text { Classified } \\
\text { Data }\end{array}$ & $\frac{\dot{J}}{\pi}$ & 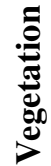 & 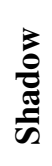 & 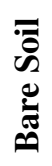 & 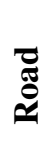 & 象 & $\begin{array}{l}\text { Total } \\
\text { Row }\end{array}$ & $\begin{array}{c}\text { Producers } \\
\text { Accuracy }\end{array}$ & $\begin{array}{c}\text { Users } \\
\text { Accuracy }\end{array}$ \\
\hline Water & 55 & 5 & 2 & 0 & 0 & 0 & 62 & $90.16 \%$ & $88.71 \%$ \\
\hline Vegetation & 0 & 46 & 0 & 2 & 0 & 1 & 49 & $90.20 \%$ & $93.88 \%$ \\
\hline Shadow & 0 & 0 & 42 & 0 & 0 & 2 & 44 & $77.87 \%$ & $95.46 \%$ \\
\hline Bare Soil & 0 & 0 & 5 & 42 & 2 & 1 & 50 & $84.00 \%$ & $84.00 \%$ \\
\hline Road & 6 & 0 & 5 & 3 & 33 & 2 & 49 & $60.00 \%$ & $67.35 \%$ \\
\hline Building & 0 & 0 & 0 & 3 & 20 & 64 & 87 & $91.43 \%$ & $73.56 \%$ \\
\hline $\begin{array}{l}\text { Total } \\
\text { Column }\end{array}$ & 61 & 51 & 54 & 50 & 55 & 70 & 341 & & \\
\hline
\end{tabular}

Overall accuracy $82.70 \%$

overall kappa statistics 0.7913

\subsubsection{Rural area}

Figure (5.b) shows misclassification in the most classes corresponding to pixelbased image classification method. Its error matrix is given in table (9). It can be seen that the overall accuracy is $67.21 \%$ and overall kappa statistics is 0.6081 . 


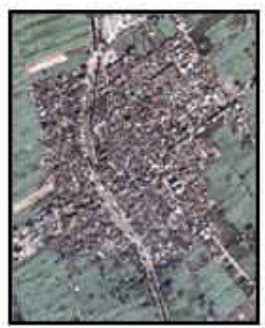

a) Original image

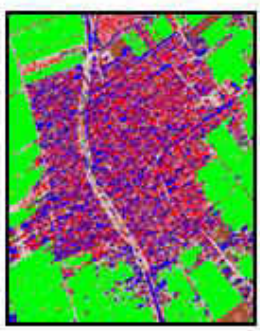

b) Pixel classification

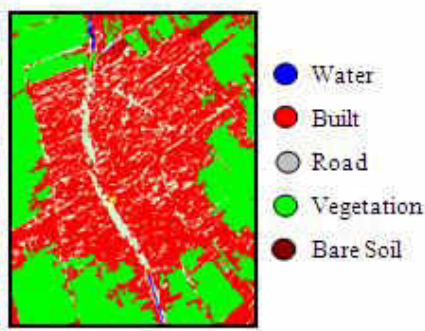

c) Object classification

Fig. 5. Pixel-based and object-based classification results of the rural area

The rural area is characterized by unpaved roads and small buildings with irregular shapes and distribution which leads to misclassification in the most classes. On the other hand, the difference in contrast between vegetation and man made features lead to extract vegetation with high producer's accuracy (95.38\%) and user's accuracy (84.93\%). Also this makes it easier to define the borders of the built up areas of the village.

In object-based image classification method (Figure- 5.c) the narrow roads can be extracted with higher efficiency. The error matrix of this method is found in table (10). It can be seen that the overall accuracy is $80.76 \%$ and overall kappa statistics is 0.7689 .

\section{Table 9.}

The confusion matrix for pixel-based classification of the rural area

\begin{tabular}{|c|c|c|c|c|c|c|c|c|c|}
\hline $\begin{array}{l}\text { Classified } \\
\text { Data }\end{array}$ & 离 & 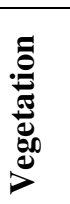 & $\frac{\vec{\sigma}}{\frac{\pi}{\pi}}$ & 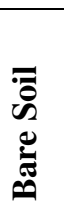 & ڤ్ & 曷 & $\begin{array}{l}\text { Total } \\
\text { Row }\end{array}$ & $\begin{array}{l}\text { Producers } \\
\text { Accuracy }\end{array}$ & $\begin{array}{l}\text { Users } \\
\text { Accuracy }\end{array}$ \\
\hline Water & 51 & 1 & 28 & 5 & 1 & 3 & 89 & $96.23 \%$ & $57.30 \%$ \\
\hline Vegetation & 0 & 62 & 0 & 11 & 0 & 0 & 73 & $95.38 \%$ & $84.93 \%$ \\
\hline Shadow & 1 & 0 & 29 & 1 & 2 & 0 & 33 & $42.65 \%$ & $87.88 \%$ \\
\hline Bare Soil & 1 & 0 & 3 & 33 & 6 & 4 & 47 & $53.23 \%$ & $70.21 \%$ \\
\hline Road & 0 & 2 & 1 & 10 & 38 & 22 & 73 & $66.67 \%$ & $52.05 \%$ \\
\hline Building & 0 & 0 & 7 & 2 & 10 & 35 & 54 & $54.69 \%$ & $64.81 \%$ \\
\hline $\begin{array}{l}\text { Total } \\
\text { Column }\end{array}$ & 53 & 65 & 68 & 62 & 57 & 64 & 369 & & \\
\hline
\end{tabular}

Overall accuracy $67.21 \% \quad$ overall kappa statistics 0.6081 


\section{Table 10.}

The confusion matrix for object-based classification of the rural area

\begin{tabular}{|c|c|c|c|c|c|c|c|c|c|}
\hline $\begin{array}{l}\text { Classified } \\
\text { Data }\end{array}$ & 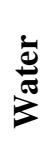 & 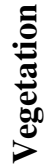 & $\frac{\tilde{\sigma}}{\tilde{D}}$ & 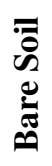 & 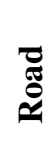 & 尝 & $\begin{array}{l}\text { Total } \\
\text { Row }\end{array}$ & $\begin{array}{c}\text { Producers } \\
\text { Accuracy }\end{array}$ & $\begin{array}{c}\text { Users } \\
\text { Accuracy }\end{array}$ \\
\hline Water & 53 & 0 & 0 & 0 & 0 & 0 & 53 & $100.00 \%$ & $100.00 \%$ \\
\hline Vegetation & 0 & 61 & 0 & 4 & 5 & 1 & 71 & $93.85 \%$ & $85.92 \%$ \\
\hline Shadow & 0 & 0 & 58 & 0 & 4 & 2 & 64 & $85.29 \%$ & $90.63 \%$ \\
\hline Bare Soil & 0 & 0 & 0 & 41 & 4 & 3 & 48 & $66.13 \%$ & $85.42 \%$ \\
\hline Road & 0 & 0 & 10 & 4 & 40 & 13 & 67 & $70.18 \%$ & $59.70 \%$ \\
\hline Building & 0 & 4 & 0 & 13 & 4 & 45 & 66 & $70.31 \%$ & $68.18 \%$ \\
\hline $\begin{array}{l}\text { Total } \\
\text { Column }\end{array}$ & 53 & 65 & 68 & 62 & 57 & 64 & 369 & & \\
\hline
\end{tabular}

Overall accuracy $80.76 \%$ overall kappa statistics 0.7689

\subsection{Quantitative analysis of the results}

Comparing the results of the accuracy assessment for both techniques (pixel-based and object-based classification) is given in table (11) and represented in (Figure -6). Generally, it can be seen that the accuracy of object-based image analysis method is greater than that of pixel-based analysis one for the same set of images of the studied areas. It has been noticed that object-based image analysis produces classification results closer to human interpretation results, free of speckled appearance, and with comparatively higher accuracies.

Table 11.

Comparison between pixel-based and object-based accuracy

\begin{tabular}{|c|c|c|c|c|c|c|}
\hline $\begin{array}{l}\text { Classification } \\
\text { Method }\end{array}$ & \multicolumn{2}{|c|}{ Accuracy } & $\begin{array}{c}\text { Good } \\
\text { planned }\end{array}$ & $\begin{array}{c}\text { Semi- } \\
\text { planned }\end{array}$ & $\begin{array}{c}\text { Un- } \\
\text { planned }\end{array}$ & $\begin{array}{c}\text { Rural } \\
\text { area }\end{array}$ \\
\hline \multirow{7}{*}{$\begin{array}{l}\text { Pixel-based } \\
\text { classification }\end{array}$} & \multirow{2}{*}{\multicolumn{2}{|c|}{$\begin{array}{l}\text { Overall Accuracy } \\
\text { Overall Kappa }\end{array}$}} & $86.42 \%$ & $73.60 \%$ & $69.21 \%$ & $67.21 \%$ \\
\hline & & & 0.83 .69 & 0.6829 & 0.6294 & 0.6081 \\
\hline & \multirow{5}{*}{$\begin{array}{l}\text { producer's } \\
\text { accuracy }\end{array}$} & Water & $96.08 \%$ & $96.00 \%$ & $90.16 \%$ & $96.23 \%$ \\
\hline & & Vegetation & $81.13 \%$ & $79.25 \%$ & $78.43 \%$ & $95.38 \%$ \\
\hline & & Bare Soil & $91.07 \%$ & $84.48 \%$ & $66.00 \%$ & $53.23 \%$ \\
\hline & & Road & $77.59 \%$ & $68.57 \%$ & $43.64 \%$ & $66.67 \%$ \\
\hline & & Building & $89.29 \%$ & $51.35 \%$ & $61.43 \%$ & $54.69 \%$ \\
\hline \multirow{7}{*}{$\begin{array}{l}\text { Object-based } \\
\text { classification }\end{array}$} & \multirow{2}{*}{\multicolumn{2}{|c|}{$\begin{array}{c}\text { Overall Accuracy } \\
\text { Overall Kappa }\end{array}$}} & $95.99 \%$ & $85.60 \%$ & $82.70 \%$ & $80.76 \%$ \\
\hline & & & 0.9518 & 0.8269 & 0.7913 & 0.7720 \\
\hline & \multirow{5}{*}{$\begin{array}{l}\text { producer's } \\
\text { accuracy }\end{array}$} & Water & $100.00 \%$ & $100.00 \%$ & $90.16 \%$ & $100.00 \%$ \\
\hline & & Vegetation & $98.11 \%$ & $88.68 \%$ & $90.20 \%$ & $93.85 \%$ \\
\hline & & Bare Soil & $91.07 \%$ & $84.48 \%$ & $84.00 \%$ & $66.13 \%$ \\
\hline & & Road & $93.10 \%$ & $90.00 \%$ & $60.00 \%$ & $70.18 \%$ \\
\hline & & Building & $100.00 \%$ & $72.97 \%$ & $91.43 \%$ & $70.31 \%$ \\
\hline
\end{tabular}




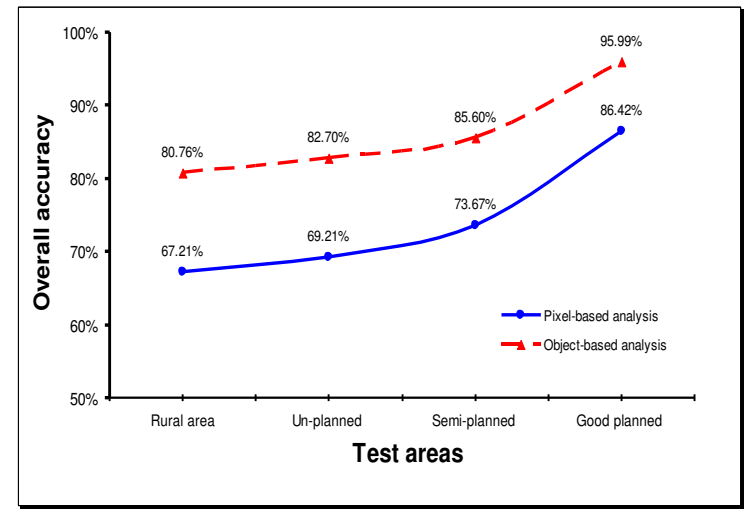

Fig. 6. Comparison of the classification accuracies of (pixel/and object-based methods) in correspondence with test areas.

Also, the above results showed that:

- Maximum Likelihood is a well established pixel-based method which is able to obtain higher classification accuracy.

- Object-based image analysis gives the highest accuracy with the good planned area which reaches to $95.99 \%$, while pixel-based one obtained $86.42 \%$ accuracy.

- The classification accuracy of both methods increases as the planning of area increase.

- The difference in accuracy values between object-based analysis and pixel-based one is decreasing with the increasing in the planning of the area.

- IKONOS (IHS) pan-sharpened image produces suitable feature extraction results.

- The main problems for the process of feature extraction are the shadow, neighbored buildings and trees particularly for narrow roads.

\section{Conclusions}

In correspondence with the results of the present work with respect to Egyptian environment, it can be concluded that:

- It can be concluded that Pixel-based classifier was found to be not optimal one for the land-cover classification of high resolution image. The cause is that, when several land-cover classes are confused together, then the information of neighboring objects is necessary for the definition of those classes.

- The identification of the land-cover types can leads to a successful classification using rule-based approach in the Object-based classification.

- The Maximum Likelihood classifier result in greater producer's and user's accuracies than the other ones for almost classes in pixel-based classification.

- It is found that the two classification methods (Pixel-based and Rule-set Objectbased) can extract much more information in planned areas not only because of the size and shape, but also because of its density.

- Overall, it is concluded that the Object-based image analysis results in higher accuracies than the Pixel-based method. 
Faten A. Mostafa et al., The optimal method for classifying high resolution satellite images .....

\section{REFERENCES}

[1] Jensen, L., F., and Gorte, B., G., "Principle of Remote Sensing" Chapter 12 Digital image classification, ITC, Enchede, 2nd Edn. The Netherlands, 2001.

[2] Tso, B., and Mather, P., M., "Classification methods for remotely sensed data". Taylor and Francis, Inc, 2001.

[3] Wenxia, W., and Xiuwan, C., "Object-oriented information Extraction and Application in High-resolution Remote Sensing image". Geoscience and Remote Sensing Symposium, IGRASS, pp.3803-3806, 2005.

[4] Sun, D., F., Yang, J., H., and Liu, S., X., "Application of High Spatial Remote Sensing Images in Land Use Classification and Change Monitoring" .Transactions of the CSAE, 18 (2): pp.160-164, 2002.

[5] Benz, U.C., Hofmann, P., Willhauck, G., Lingenfelder, I., and Heynen, M., "Multiresolution object-oriented fuzzy analysis of remote sensing data for GIS-ready information". ISPRS J. Photogrammetry and Remote Sensing, 58: pp239-258, 2004.

[6] Schwarz, M., Steinmeier Ch., and Waser L., "Detection of storm losses in alpine forest areas by different methodic approaches using high-resolution satellite data". DEFINIENS eCognition website, http://www.definiens-imaging.com, 2000.

[7] Wang, L., Sousa, W. and Gong P., "Integration of object-based and pixel-based classification for mangrove mapping with IKONOS imagery". International J. of Remote Sensing, 25(24): pp5655-5668, 2004.

[8] Willhauck G., "Comparison of object-oriented classification techniques and standard image analysis for the use of change detection between SPOT multispectral satellite images and aerial photos". In: Proceedings, ISPRS, Vol. XXXIII, 2000.

[9] Sun X., "Comparison of pixel-based and object-oriented approaches to land cover classification using high- resolution IKONOS satellite data". Master's Thesis, University of Minnesota, 2003.

[10] ERDAS, "Erdas field guide", fifth edition, version 8.4 (Erdas), Atlanta, USA, 1999.

[11] Chavez, P., Sides, S., and Anderson, J., "Comparison of Three Different Methods to Merge Multiresolution and Multispectral Data: Landsat TM and SPOT Panchromatic" Photogrammetric Engineering \& Remote Sensing, No. 57, No. 3, pp.295-303, 1991.

[12] Garzelli, A., Nencini, F., Alparone, L., Aiazzi, B. and Stefano Baronti, "Pan-Sharpening of Multispectral Images: A Critical Review and Comparison. Geoscience and Remote Sensing Symposium” IGARRSS, No. 1, pp. 81-84, 2004.

[13] Oguz, G., and Jie, S., "A Statistical Approach to Multiresolution Image Fusion”. Pecora 16 "Global Priorities in Land Remote Sensing" Octaber 23-27, Sioux Falls, South Dakota, 2005.

[14] Wang, J., and Zhang, Q.,”Applicability of a gradient profile algorithm for road network extraction: Sensor, resolution and background considerations" Canadian Journal of Remote Sensing, 26(5):pp.428-439, 2004.

[15] Congalton, R., "A Review of Assessing the Accuracy of Classifications of Remotely Sensed Data”. Remote Sensing of Environment, vol.37, pp.35-46, 1991.

[16] Lillesand and Kiefer., "Remote sensing and image interpretation (third edition)". John wiley and Sons, Inc. New York, 1997.

[17] Malgorzata, V., W., "Object-based Classification of Urban Land Cover Extraction Using High Spatial Resolution Imagery". International Scientific Conference on Sustainable Development \& Ecological Footprint, 2012.

[18] Trimble Germany GmbH, "eCognition Developer Reference Book", Version V.8.7.2, 80339 Munchen, Germany. pp.37, 2012. 


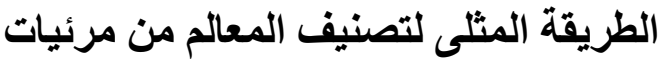

\section{الأقمار الصناعية عالية الدقة للبيئة المصرية مرنية}

\author{
الملخص العربي
}

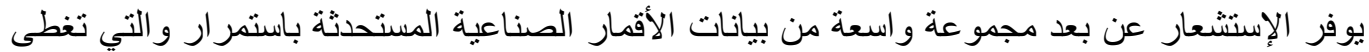

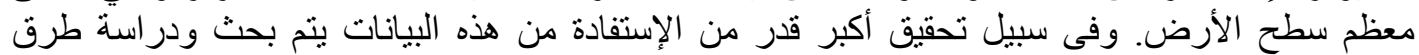
أوتوماتيكية جديدة لتحليل وتصنيف تللك البيانات. و على مدى السنوات الماضية اعتمدت طرق الإن التصنيف

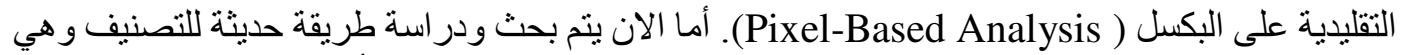
(Object-Based Analysis)

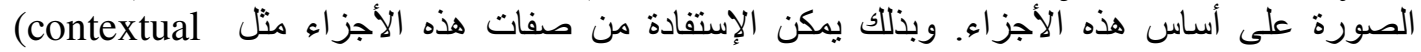
information, texture, shape) أنسب وأدق الطرق من تلك الطرق المتاحة لتحليل بيانات مرئيات الاقمار الصناعية واستخر اج المعلومات

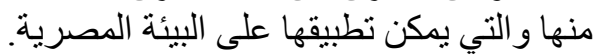

وقد أجريت الدراسة باستخدام مرئية ملتقطة بواسطة القمر الصناعي IKONOS توضح مدينة أسيوط

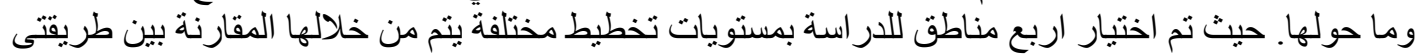
التصنيف Pixel-Based Classification و Object-Based Classification . حيث أظهرت النتائج أن طريقة Object-Based Classification هي الأفضل لهذ الغرض وتمنلك المزيد من المزايا عن طريقة من Pixel-Based Classification مستوى تخطيطها كلما أمكن استخر اج المعالم منها بدقة أكبر في كلتا الطريقتين. 